\title{
The Impact in Customs Efficiency of the ITSW: Mexico Case of Study
}

\author{
América I. Zamora-Torres, César Navarro-Chávez, Oscar Hugo Pedraza-Rendón
}

Instituto de Investigaciones Económicas y Empresariales, Universidad Michoacana de San Nicolás de Hidalgo, Morelia, México. Email: americazt@hotmail.com

Received April, 2013

\begin{abstract}
The evolution and grow of international trade has made the task assigned to customs services more important and complex. Now day's customs administration is a relevant regulatory operator in international trade as facilitator and accelerator of trade. However, the study of efficiency on the public sector is more complex than the study of efficiency in the private, profit-oriented sector; due to the fact that public sector efficiency can be defined as capacity to achieve goals instead of perceiving profits. The aim of this research is to identify those areas which yield the greatest cost/efficiency gains from the implementation of the e-service system International Trade Single Window (ITSW) and to note the obstacles or disadvantages present on the implementation of the ITSW in Mexico as a case of study. The findings point out that, according to the first result of the implementation of the ITSW, Mexico has made good progress related to the efficiency of international trade procedures, simplifying the flow of information between traders and customs administration and reducing the time in customs clearance in $20 \%$.
\end{abstract}

Keywords: Efficiency; Customs; Public Services; E-System; ITSW; International Trade; Mexico

\section{Introduction}

In the past twenty years, international trade has growth twice faster than de GDP. Many economies ensure that the international trade plays a major role in the economic growth [1].

International trade involves goods crossing borders for what is required to covert a number of procedures. Some of these procedures pertain to issues of security and standards, while others deal with customs. Customs clearance is a force step on international trade which impacts on a country's competitiveness that prompted traders and political leaders to seek out ways to make their customs organizations more effective and efficient.

However this is not a simple task due to the constantly changing and challenging global trade that has become increasingly difficult of the growing complexities of trade policy owing to the proliferation of regional and international agreements, the greater sophistication of traders, and the multiple and shifting objectives imposed on customs [2]. On the other hand, the scrutiny upon governments has demanded public entities to increase the efficiency in using the resources they manage.

Many countries including Mexico had implemented the e-system International Trade Single Window (ITSW) in order to improve the efficiency of customs related to international trade. The single window is defined by the
World Customs Organization (WCO) [3] and World Trade Organization (WTO) [4] as "a cross-border intelligence facility that allows parties involved in trade and transport to lodge standardized information and documents with a single entry point to fulfill all import, export and transit related regulatory requirements" or "A platform to allow traders to submit international trade import, export or transit- data required by government departments or agencies once only through a single electronic interface thereby fulfilling all the regulatory requirements in respect of each transaction".

The aim of this work is to identify those areas which yield the greatest cost/efficiency gains from the implementation of this e-service system and to note the obstacles or disadvantages present on the implementation of the ITSW in Mexico as a case of study.

\section{Customs, Efficiency Concept and Literature Review}

Every organization that want to stand out or survive the past of the time is looking for be efficient. When we talk about efficiency different concepts pop out. The efficiency defined as the degree of optimization of the result obtained in relation with the resources used [5]. Efficiency as the relationship between goods and services consumed and the goods and services produced; or what 
is the same, services provided (outputs) in relation to the resources used to such an effect (inputs) [6]. Whereas in the private sector inputs and outputs are expressed in financial terms, identification of inputs and, especially, outputs however in the public sector is much more complex [7].

Observing the public sector, effectiveness, which can be defined as capacity to achieve goals, gains a greater importance than efficiency [8]. In the public services there is no direct correlation between revenues and expenses [9]. The political system is oriented primarily to the achievement of goals defined in the political process, regardless of the cost-benefit ratio.

The assessment of the performance of the public sector has long been a topic of interest to economists, public administration scholars and management scientists [10] [11]. Some studies analyzed the productivity of government and compared the productivity of whole public sectors of different countries. That is the case of Afonso, Schuknecht and Tanzi [12] have carried out an international comparison of public sector efficiency based on the public sector performance (PSP) and efficiency (PSE) indicators. These indicators comprise a composite and seven sub-indicators. Four of them are "opportunity" sub-indicators that take into account administrative, education and health outcomes and the quality of public infrastructure and those that support the rule of law and a level playing-field in a market economy. Three other indicators reflect the standard "Musgravian"' tasks for government: allocation, distribution and stabilization. After defining indicators, the efficiency is measured via the non-parametric frontier technique.

Other studies focus on the productivity measurement in the public sector can also take place at the level of the organization and from a "bottom up" or service-user perspective [13]. The World Bank has adopted this approach with regard to assessing some aspects of the effects of regulation with the development of their Doing Business database, where three indicators from the database are particularly relevant to the assessment of public administration quality and productivity.

Relatively to customs administration have being develop some systems to measure efficiency most of them in Europe. The European Commission has established its Measurement of Results (MoR) project for the customs services of member states. Work on measuring the results of customs activities performed by member states is underway and the results achieved enable member states to compare their performance to the Community standard and act to improved customs operations where necessary.

A few years ago the role of customs was to be able to enforce regulation tariffs, non- tariffs and administrative regulations for all products that enter and leave the country, respecting international trade agreements [2]. How- ever, consumers demand has been changing as international trade with it. Whereby, customs under this trend should be facilitators of foreign trade through the tax and regulatory simplification.

Overall, the role of the customs service is to be a business facilitator, policy adviser and implementer and safety provider. The proper execution of these functions can foster a fair market, ensure timely delivery and reduce costs of international trade, which leads to the competitive advantage of firms and nations in the global value chain [14].

Currently, customs are confronted to a rapidly changing environment: changing patterns of production and consumption intensified international trade, new global threats... In this context, customs play a major role by ensuring a constant balance between protecting society and simplification of trade.

Customs efficiency has a significant impact on reducing cost associated with trade and business performance management, so a close link between competitiveness in international trade and customs can be identified [14]. In the other hand, a poor function of customs administration may indeed affect the improvements that have been made in other areas related to international trade [2].

In such conditions customs administrations, being relevant regulatory operators in international trade and goods movements, accept more important and complex tasks. To begin with, customs administrations are expected to facilitate and accelerate international trade and transport [7].

\section{Worldwide International Trade Single-Window Developments}

The ITSW is a concept that has been implemented in a variety of ways in different countries the past years. Historically, the concept of a single-window was developed by the United Nations Economic Commission for Europe (UNECE) and countries in other jurisdictions as Korea, Singapore, Thailand, Chile Japan and Mongolia [15].

The main objective of the implementation of the ITSW is to achieve trade facilitation or the simplification and harmonization of international trade procedures.

Governments and the import/export, shipping, logistics and transport communities have established a range of agency and country-specific regulatory and operational requirements for international trade. However, there has been limited coordination between these groups, both at the national and the international levels. As a result, traders are faced with a confusing set of stringent, overlapping and onerous reporting requirements, often including redundant, repetitive and outdated or superseded regulations. These requirements come in the guise of forms, systems, data sets, data models, and electronic 
messages, not to mention personal voice communications, and unwritten, informal demands [4].

Governments and trade have to develop and continuously maintain different systems to meet these myriad requirements. This adds onerous costs and overhead to all parties, both in terms of fiscal resources and the timeliness and accuracy of data. The problem has become more acute in recent years with the requirements for faster information delivery, often in advance of shipping, for security and other purposes, and the expanding requirements of data harmonization in international supply chains. The ability to handle data efficiently and swiftly has, in fact, become a key element in international competitiveness, especially in international supply chains [16].

In order to overcome this complex system of data submission and regulatory control the single-window was designed.

The main goals of the implementation of the ITSW can be divided according to the international trade actor as follow [4]:

1) For the government

- More efficient and productive use of resources;

- Enhanced collections of fees, duties and penalties;

- More comprehensive, streamlined and automated business compliance to Government legislative and regulatory requirements, including the terms of international trade treaties;

- Enhanced risk analysis and management and improved security;

- Reductions in corruption and illegal trade activities, enhanced transparency and accountability.

2) For the trader

- Cost reductions through minimized clerical efforts, time taken to reduce and to eliminate delays, and more predictable, reliable and authoritative decisions;

- Faster goods clearance, exception handling and dispute resolution, leading to reduced inventory holding costs;

- Predictable and reliable consignment clearance and availability of advanced goods release information;

- Reduction in face-to-face meetings, greater transparency and reduced opportunities for rent seeking and corruption.

3) For the logistic operator

- Faster movement of goods through formalities and trade junctions, leading to better and more productive utilization of resources;

- Reliable information on timing of goods movement, allowing accurate scheduling, allocation of resources and improved accuracy of information provided to clients;

- More productive and flexible use of human resources;

- The ability to accurately schedule goods collection and discharge times and locations;

- Better end-to-end audits of operation.

It is worth nothing that every region is looking to achieve specific goals through the ITSW window for example, The European Union, is attempting to optimize the efficiency of border crossings within the European trading community, while ECOWAS ${ }^{1}$ is concerned with controlling smuggling, hijacking and other illegal activities. ASEAN ${ }^{2}$ is attempting to introduce efficiencies in import and exporting between the ten ASEAN countries by deploying common formatted documents in each member country. APEC is concerned with the implementation of a safe and secure supply chain. It includes the concept of an end-to-end supply chain track and trace system, to enable regulators to trace dangerous goods from manufacturer, or source, right through to the ultimate end user [17].

\section{International Trade procedures in México before ITSW}

The real value of ITSW to Mexico can only be judged in terms of prevailing conditions which are significantly different to those in other countries where ITSW has delivered quantified benefits so it would be unwise to presume similar gains can be achieved.

Nevertheless the progress made by the customs administration is still a big problem the health and security control and therefore data has to be provided to the authorities, and shipments need to be inspected, as a result traders have to fill in numerous forms, often duplicated information sometimes in different formats (see Figure 1).

Nowadays in Mexican international trade are involved about 30 actors (shipping agents, customs agents, exporters, importers...) which used 40 different documents along the supply chain, customs, nontariff restrictions and regulations among others. The customs clearance process takes at least five days passing by 165 paperwork's where are capture around 200 different data that is capture the 60 a 70 per cent of the times more that one's [18].

The Figure 2 shows the permits issued by different government agencies involved in the process of foreign trade.

\section{Expectative of the E-System ITSW Implementation in México}

The main goals pretended with the implementation of ITSW were the decrease of corruption and fiscal evasion, improve the logistic process and the legal certainty as to contribute to a green planet.

\footnotetext{
${ }^{1}$ Economic Community Of West African States.

${ }^{2}$ Association of Southeast Asian Nations.
} 


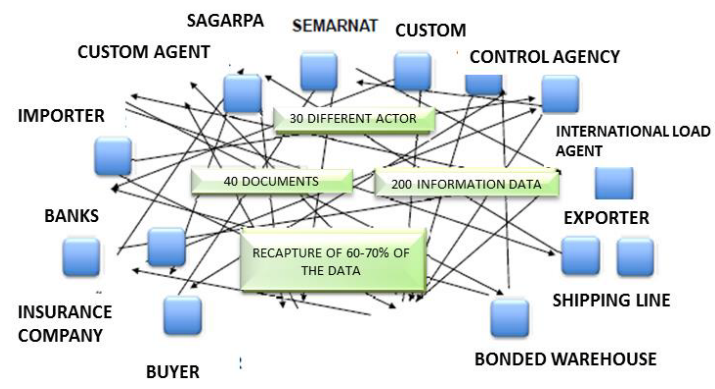

Figure 1. International business flowchart before ITSW.

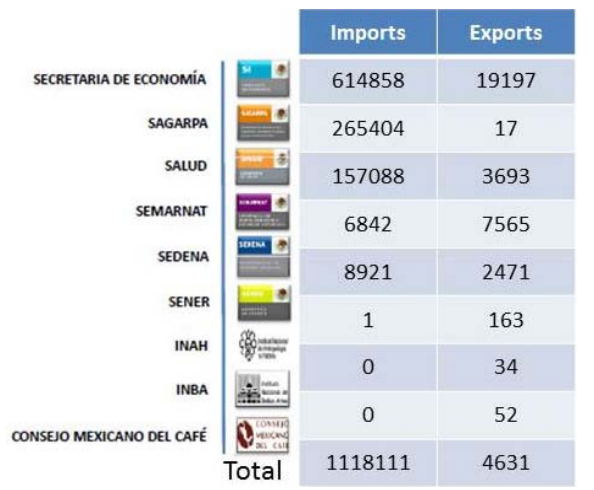

Figure 2. Permits issues by government agencies.

According to the Doing Business report most of the delays in the import export process are due to the time take it in the documents preparation. Until the year 2011 the days take in Mexico to prepare the paperwork were 14 days to exports and 17 days to imports with an average cost of 1470USD and 2050USD respectively [19]. One of the targets of the implementation of the ITSW in Mexico was to reduce the delays and costs in these parts of the process, in order to facilitate and accelerate the preparation of the governmental paper, and the interconnection between private sector windows (transport services and financial entities among others). Therefore one of the objectives of the implementation of ITSW was to place Mexico from the $74^{\text {th }}$ at the $54^{\text {th }}$ in the Trade Facilitation World Bank Index [18].

The estimated time that used to took past through the customs inspection was around 165 minutes. The time of customs inspection is pretended to be reduce in an $11.3 \%$ as a result of the recognition at the time of the verification in a mobile device [18].

As results of the time reduction in recognition the transport operations could increase by $50 \%$ and the process of clearance of good reduce in $80 \%$ ( 1 day). The achievement of these objectives leads to the optimization of human resources at customs administration in 21\% which represents about the \$12 19806 USD [18].

\section{First Results}

Even so many countries had implement the ITSW the last few years Mexico has only one year past since the implementation of this e-system in 2012.

The ITSM phases of implementation were:

(a) The technology of a single point of access that could facilitate communications between a community of other systems, but users must have dedicated access points, just like access to an email service provider;

(b) The use of a single user ID and password sign on.

(c) The single submission of data so that no matter who and how many different users make use of the originally submitted data, it only has to be entered into the system by one nominated user; preventing duplica- tion, several types of error and transcription mistakes, multiple conflicting versions of information and associ- ated mistakes.

(d) Point of decision-making allowing that each signon enables the user to apply for, and receive, licenses and permits, to make, and obtain approval for, customs declarations, to track and trace consignment progress and location, estimate time for goods arrival and availability for collection, to book and confirm transport and to obtain goods release...

(e) A gateway to online banking facilities, operating all around the clock with a real time confirmation of transaction payments by the implementation of a single point of payment of any service related to the export/ import procedures such as customs, the port, shippers, the container handler, transport, freight forwarders, customs brokers and a range of messengers and intermediaries all have to be paid at some stage by cargo importers and exporters (see Figure 3).

From June $1^{\text {st }} 2012$ to January $30^{\text {th }} 2013$ were performed 7.7 millions of operations through the ITSW.

In the ITSW are register the $96.4 \%$ of the import register (70 000 records approx.).

The first results shows that with the ITSW implementation the time in customs clearance procedures decrease in $20 \%$, even when hasn't been completed the digitization process of the import/export proceedings.

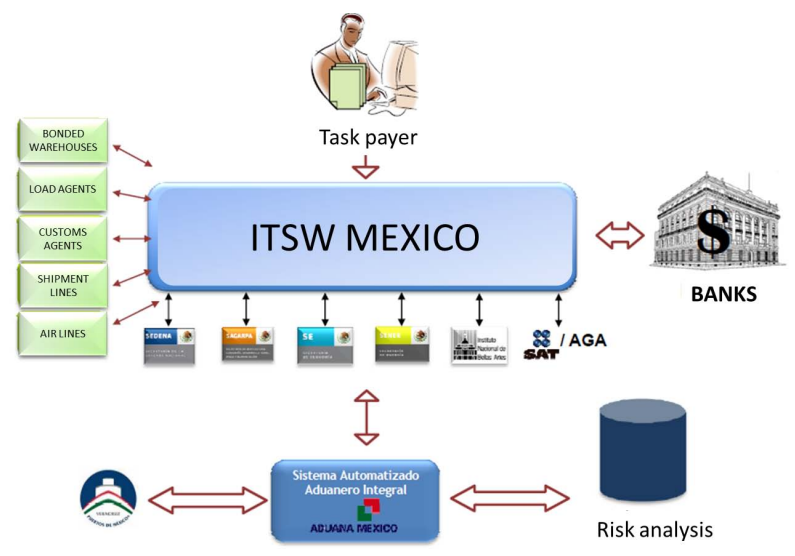

Figure 3. ITSW international business flowchart. 
The time that take past through the customs inspection decrease in 30 minutes that represent a $20 \%$ least than before the implementation of ITSW. Also where simplify 40 documents, 165 paperwork's and 200 different data.

Nevertheless not all businesses involved in International trade benefit equally from the ITSW, for those business already moving free circulation goods within the NAFTA or under the frame of an international trade sign by Mexico that allows these movements the immediate significance of the ITSW is minimal; given that some goods are more controlled than others; so there is a correlation between the benefits of ITSW to the trader and the complexity of the existing procedures.

Another aspect to consider is the implementation cost for micro and small business that according to Jaso [20] oscillate around 7thousand dollars due to the necessity of acquire the computer equipment, internet networks and the training in order to be part of the e-system.

Regarding to the legal frame one of the major problems that had to be faced in order to implement ITSW in Mexico case was the necessity of restructures some legislation and rules concerning to the use of electronic signature, elimination of requirements, electronic notifications, legal representatives, shareholders among others.

\section{Conclusions}

Any conclusion derivate from this first analysis is only preliminary because the implementation of the program is quite recent and it has to be measure by the test of the time and the unexpected task that will show up. Despite of these remarks the initials conclusions are that Mexico has made good progress related to the efficiency of international trade procedures simplify the flow of information between traders and government and reducing the time in customs clearance (20\% decrease).

It is important to point out that even so these ITSW e-system has been implemented on a number of countries the variation between conditions in individual countries makes difficult and complex to defined the efficiency of the program as a result of the financial and resources capacities, the current legal codes, business practices, trade patterns and needs, the size of the economy, geographical factors, stability... that makes relevant the study of individual cases.

\section{Discussion}

At the beginning of this study it was considered that the most significant measure of the benefit of an ITSW would probably be in its potential for harmonizing the provision of data and eliminating duplication. Nevertheless the savings in time and money in this area for the trader and the customs administration (and any other government agency involved in the process) must be added significant in terms of the most efficient operation of its control agencies through sharing information and co-ordinating activities which allows the goods movement through the various control system with greater speed and transparency.

Even the functionality of the e-system there are still some problems with the implementation of the operation, particularly with the micro and small companies who are entering to the global markets and cannot face the cost of ITSW. These raise the question about the marginalization of the benefits of the ITSW and the possible enlargement of the disparity of economic growth.

\section{Acknowledgements}

Professor América I. Zamora Torres shows gratitude for the financial support from the National Council for Science and Technology (Consejo Nacional de Ciencia y Tecnología, CONACYT) in Mexico. The usual caveats apply.

\section{REFERENCES}

[1] Ministry of Economy, "Single Window," Commercial Facilitation, 2011.

[2] L. De Wulf, and J. B. Sokol, "Customs Modernization Handbook,” The World Bank, Washington, D.C., 2009.

[3] World Customs Organization, "How to Build a Single Window Environment,” WCO Compendium, Vol. 1, 2011, p. 11.

[4] Escwa, "Key Factors in Establishing Single Window for Handling Import/Export Procedures and Formalities: Trade Facilitation and Single Window," 1st Edition, United Nations, New York, 2011.

[5] I. G. Igae, "Goal Setting and Performance Measurement in the Public Domain,” MEH, Madrid, Spain, 1997.

[6] A. E. Aeca, "Management Indicators for Public Entities," Series of Principles of Managerial Accounting, 2nd Edition, Madrid, Spain, 1997.

[7] A. Benazic, "Measuring Efficiency in the Croatian Customs Service: A Data Envelopment Analysis Approach,” Financial Theory and Practice, Vol. 36, No. 2, 2012, pp. 139-178. doi:10.3326/fintp.36.2.2

[8] E. Pusić, "Međuovisnost Djelatnosti i Ustrojstva u Upravnim organizacijama," Javna uprava u demokratskom društvu, Zagreb, Institut za javnu upravu, 1999, pp. $1-26$.

[9] L. Von Mises, “Birokracija. Zagreb,” Institut za javne financije, 2005.

[10] C. A. K. Lowell, "Performance Assessment in the Public Sector,” in K. J. Fox (Ed.), Efficiency in the Public Sector Dortrecht, Kluwer Academic Publishers Group, 2002, pp. 11-35.

[11] R. Boyle, "Measuring Public Sector Productivity: Lessons from International Experience," Institute of Public Administration, Dublin, Germany, 2006. 
[12] A. Alfonso, L. Schuknecht and V. Tanzi, "Public Sector Efficiency: An International Comparison,” European Central Bank, Working paper, No. 242, Germany, 003.

[13] R. Boyle, "Public Sector Productivity Measurement: An Impossible Task,” In C. Ailward and R. O'Toole (Eds), Perspectives on Irish productivity, Forfas, Dublin, 2007, pp. 100-115.

[14] Z. Shujie and S. Zhao, "The Implication of Customs Modernization on Export Competitiveness in China," Chapter 5, En U. N. (ESCAP), Impact of Trade Facilitation on Export Competitiveness: a Regional Perspective United Nations Economic and Social Commission for Asia and the Pacific (ESCAP), 2009, pp. 121-131.

[15] I. Obi, "Customs Launch Single-Window E-services to Facilitate Trade,” Vanguard, 2013.
[16] G. Linington, "International Trade Single Window and Potential Benefits to UK Business,” SITPRO, Oxford House, London, 2005, p. 5.

[17] WCO, "Single Window Environment," WCO, web pages on the WCO website www.wcoomd.org, Brussels, 2008.

[18] SAT, "Mexican International Trade Single Window," SHCP, Tax Administration System, Mexico City, 2011, pp.13-15.

[19] The Word Bank Group, “Doing Business 2011,” 9th Edition, World Bank, Washington, 2012.

[20] I. Jaso, “SMEs Slow to Stop High Costs,” PWC, 2013. http://www.elsiglodetorreon.com.mx/noticia/715237.fren an-a-pymes-altos-costos-de-ventanilla-unica.html\# 